\title{
Montaigne, Essais, I, 56. «Des prières»
}

\section{Michele Mastroianni}

\section{(2) OpenEdition}

\section{Journals}

\section{Edizione digitale}

URL: http://journals.openedition.org/studifrancesi/34571

DOI: 10.4000/studifrancesi.34571

ISSN: 2421-5856

\section{Editore}

Rosenberg \& Sellier

\section{Edizione cartacea}

Data di pubblicazione: 1 novembre 2005

Paginazione: 406

ISSN: 0039-2944

\section{Notizia bibliografica digitale}

Michele Mastroianni, «Montaigne, Essais, I, 56. «Des prières»», Studi Francesi [Online], 146 (XLIX | II) |

2005, online dal 30 novembre 2015, consultato il 18 avril 2021. URL: http://journals.openedition.org/ studifrancesi/34571; DOI: https://doi.org/10.4000/studifrancesi.34571

\section{Questo documento è stato generato automaticamente il 18 avril 2021.}

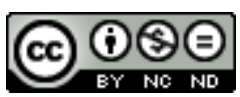

Studi Francesi è distribuita con Licenza Creative Commons Attribuzione - Non commerciale - Non opere derivate 4.0 Internazionale. 


\title{
Montaigne, Essais, I, 56. «Des prières»
}

\author{
Michele Mastroianni
}

\section{NOTIZIA}

MONTAIGNE, Essais, I, 56. «Des prières», édition annotée des sept premiers états du texte avec étude de genèse et commentaire par ALAIN LEGROS, Genève, Droz («Textes littéraires français», 558), 2003, pp. 264.

1 Il breve capitolo 56 (Des prières) del primo libro degli Essais è fondamentale per analizzare il pensiero religioso di Montaigne. Costruito come un commento al «Padre nostro», definisce in qualche modo lo statuto dell'intera opera, volutamente umanista e laica, ma «très-religieuse toujours». Nel «Padre nostro» Montaigne ritrova, a livello di riflessione sul divino, quell'associazione di misericordia e giustizia, per lui sostegno di un corretto atteggiamento nel rapporto che l'uomo istituisce con Dio. Le pagine del capitolo 56, che attirarono l'attenzione sospettosa della censura romana durante il viaggio in Italia di Montaigne, furono - d'altronde come gli Essais nel loro insieme oggetto di ripetuti interventi correttori e ripensamenti da parte dell'autore. Come ben sappiamo, se il pensiero di Montaigne è sempre in movimento - talvolta inafferrabile -, anche il testo è perennemente in fieri e pone dei problemi tremendi, d'ordine filologico e genetico, agli editori. Ora, proprio su di un segmento altamente significativo sul piano concettuale, Alain Legros compie un'operazione di ricostituzione testuale che permette di seguire la genesi e l'evoluzione del dettato di Montaigne; e questo fa pubblicando successivamente e criticamente (vengono adottati degli accorgimenti tipografici che evidenziano interventi, addizioni e varianti) il testo dell'edizione del 1580 di Bordeaux, presso Simon Millanges, quello dell'edizione di Bordeaux del 1582, sempre presso Simon Millanges (con varianti dell'edizione parigina di Jean Richer, del 1587), quello dell'edizione parigina del 1588, presso Abel L'Angelier, ancora quello dell'esemplare parigino del 1588, ma corretto e completato da Montaigne in vista di una nuova edizione, quello dell'edizione parigina del 1595 (prima edizione postuma) a cura di Marie de Gournay, sempre presso Abel L'Angelier (con varianti dell'edizione del 1598). I testi che si susseguono sono accuratamente annotati a livello di lessico e di concetti e a 
livello strettamente filologico (pp. 199-250). La densa introduzione (pp. 19-141) è un saggio esemplare di critica genetica ed offre un'interessante monografia sul pensiero religioso di Montaigne. 